\title{
Failure Analysis of Hydraulic Cylinder Bolt on Turntable Vibrating Compactor in Aluminum Processing Plant
}

\author{
Indah Permata Sari ${ }^{a, *}$, and Warman Fatra ${ }^{b, *}$ \\ a) Undergraduate student of Mechanical Engineering Department, Universitas Riau, Indonesia \\ b) Head of Material Testing Laboratory, Mechanical Engineering Department, Universitas Riau, Indonesia
}

*Corresponding author: indah.permata3119@student.unri.ac.id; warman.fatra@eng.unri.ac.id

\section{Paper History}

Received: 13-Juni-2020

Received in revised form: 16-July-2020

Accepted: 30-July-2020

\begin{abstract}
The aluminum and its alloy have several characteristics, i.e. relatively low density, high electrical and thermal conductivity and also good in corrosion resitance. The molding process of green anode blocks at an aluminum plant is carried out by an anode forming system. In this system, there is a printer called as turntable vibrating compactor or referred to as a 'shaking machine'. During 55 seconds of anode block compaction, the fluctuating stress would be received by hydraulic cylinder bolt due to vibrations of the turntable vibrating compactor. The fluctuating stress that works continuously on the bolt can increase the tendency of failure. This paper aims to find out the causing factors and alternative solution for failure of the hydraulic cylinder bolt. To determine the causes of failure, several methods are carried out, i.e. fractography investigation, metallography examination according to ASTM E3-95, hardness testing according to ASTM E92-17 and tensile testing according to ASTM E8/E8M-16a. Fractography investigation showed the failure mode of low cycle fatigue due to the application of high nominal stress. This is indicated by the presence of ratchet, beach mark, river mark and shear lip. The short life of the bolt due to the hardness and strength of the bolt after undergoing the heat treatment process $Q+T$ cannot increase its endurance limit.
\end{abstract}

KEY WORDS: Heat treatment, Fractography investigation, Metallography examination, Mechanical testing, Low cycle fatigue

\section{NOMENCLATURE}

ASTM American Standard for Testing and Material

$\begin{array}{ll}\text { HS } & \text { Shore Scleroscope Hardness Number } \\ \mathrm{HV} & \text { Vickers Hardness Number } \\ \sigma_{\mathrm{u}} & \text { Ultimate Tensile Strength } \\ \sigma_{\mathrm{y}} & \text { Yield Strength }\end{array}$

\subsection{INTRODUCTION}

The aluminum and its alloy have several characteristics, i.e. relatively low density $\left(2.7 \mathrm{gr} / \mathrm{cm}^{3}\right.$ if it is compared to steel density $7.9 \mathrm{gr} / \mathrm{cm}^{3}$ ), high electrical and thermal conductivity and also good in corrosion resistance [1]. According to Callister [1], many of these alloys are easily formed by virtue of high ductility under its $660^{\circ} \mathrm{C}$ melting point. Several common examples of aluminum alloy application, such as most of aircraft structures, food or chemical handling and storage equipment, cooking utensils up to beverage cans.

An environmentally friendly aluminum ingot is produced by using electrolysis method, which requires electrical conductance from the cathode and anode block. The anode block is produced directly through several steps in aluminum processing plant. The molding process of green anode blocks at an aluminum plant is carried out by an anode forming system. In this system, there is a printer called as turntable vibrating compactor or referred to as a 'shaking machine' by the company. This machine is operated for 24 hours a day and rests for 8 hours after 6 days of operating process. In compaction process, the mold and cover weight are locked with a hydraulic powered clamp locking device. The clamp locking device has a hydraulic cylinder with cap end head and rod end head, which is connected by four bolts.

During 55 seconds of anode block compaction, the fluctuating stress would be received by hydraulic cylinder bolt due to vibrations of the turntable vibrating compactor. The fluctuating stress that works continuously on the bolt can increase the tendency of failure. The failure of the hydraulic cylinder bolt must be prevented or immediately solved, because it is able to stop the operation, so that any other system can also disturbed. Therefore, the company's production targets could not be obtained.

Several studies have been conducted to find the cause of bolt failure. For example, the bolt fracture surface of a filter 
press in one of the studies showed the characteristics of fatigue due to progressively crack growth, stress concentration in the thread roots and surface damage that initiate failure [2]. Another study has stated that the VVCP gas compressor piston bolt failed due to compression load, which triggers bending or buckling. The crack was initiated from the stress concentration region, then grew higher and finally fractured with undirectional bending pattern [3]. In addition, 6 of the 8 fastened bolts for high-speed cylinder cap and upper ram cylinder in hydraulic press failed due to fatigue mechanism. The crack initiation and propagation were occurred on the maximum strain part due to surface damage. Incorrect assembly resulted high residual stress, which triggers failure [4]. Based on the description above, the further research is needed in order to find out the causing factors and alternative solution for failure of the hydraulic cylinder bolt on turntable vibrating compactor in aluminum processing plant.

\subsection{METHOD}

This research was conducted experimentally in Material Testing Laboratory, Department of Mechanical Engineering, Faculty of Engineering, Universitas Riau, Indonesia. Several processes of this research are described as below.

\subsection{Collection of Bolt Background Data}

The background data were collected through a manual book of the turntable vibrating compactor, machine utilization process and bolt replacement schedule information as well as fabrication workshop operator interviews.

Based on interviews, the bolt material was JIS SCM440 or equivalent to AISI 4140. The bolt failed after being used for 3 to 12 months. To increase the hardness, the bolt was heat treated. The bolts were heated in the electric furnace for 4 hours at $850{ }^{\circ} \mathrm{C}$ and held for 2 hours. Then, the bolt was oil quenched and left up to 24 hours. In order to increase the toughness and to reduce the residual stress, tempering was carried out on the bolt by heating for 3 hours at $750{ }^{\circ} \mathrm{C}$ and held for 3 hours. The bolts were cooled by using the same method as the previous quenching process.

\subsection{Preliminary Examination of Failure Bolt}

The preliminary examination was conducted by taking of pictures on the fracture surface and overall part as well as dimension measurement of failure bolt. The result of this process is shown in Figure 1.

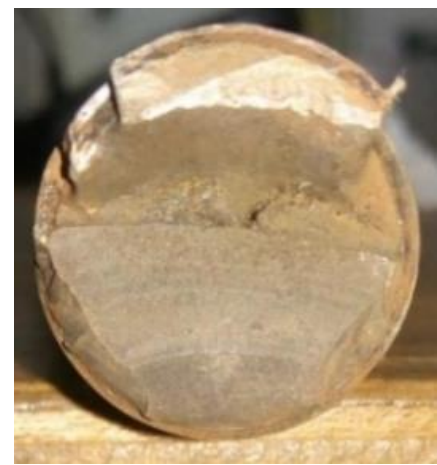

Figure 1: Fracture of failure bolt

\subsection{Specimen Preparation}

The sample consists of one failure bolt and three new bolts. The preparation processes of specimen are described as below:

a. Specimen of Fractography Investigation

The specimen was soaked in pickling solution to clean fracture from grease, corrosion and any other unexpected particles. Pickling normally involves using an acid mixture containing 8-20 Vol\% of nitric acid (HNO3) and 0.5-5 Vol\% of hydrofluoric acid (HF) [5]. This research used $\mathrm{HNO}_{3} 65 \%$ and $\mathrm{HF} 55 \%$ with final concentration of $\mathrm{HNO}_{3}$ and $\mathrm{HF}$, i.e. $13 \%$ and $2.5 \%$, respectively. Fracture surface was rinsed with clean tap water and dried by tissue. The fracture surface was captured by using mobile phone camera of Vivo type V11.

b. Specimen of Metallography Examination

The specimen was prepared according to ASTM E3-95 standard [6]. The failure specimen was mounted by using polyester resin and its hardener, then ground with 240,320 , 400, 600, 800, 1000, 1200, 1500 and 2000-grit of abrasive papers sequentially. The specimen was polished by fine alumina suspensions $(0.3 \mu \mathrm{m})$ to remove the deep scratches. Etching was conducted by soaking the testing surface into $2 \%$ nitric acid and alcohol (nital) etchant for a second. The specimen was rinsed with clean tap water at the end of every preparation process.

c. Specimen of Hardness Test

Three new bolts were cut into six for hardness test pieces with a thickness of approximately $10 \mathrm{~mm}$ and one failure specimen with a thickness of $25 \mathrm{~mm}$. The surface was ground with 240 and 800 -grit of abrasive paper on metallurgical polisher to remove all sectioning lines. For the failure bolt, this process was carried out on the crosssectional and convex surface of $10 \mathrm{~mm}$ in convex diameter.

d. Specimen of Tensile Test

Based the hardness test, six tensile test specimens were prepared according to ASTM E8/E8M-16a standard [7]. Two of the tensile test specimens were subjected to oil quenched treatment and the remaining were subjected to receiving condition.

\subsection{Test}

a. Metallography Examination

The metallography examination aims to obtain information about the phases and the microstructures contained in the failure bolt. This information was characterized by using an optical microscopy Olympus BX60MF5.

b. Hardness Test

The hardness test was conducted by Vickers method according to ASTM E92-17 standard [8], by using pyramidal diamond indenter and subjected to a load of 62.5 $\mathrm{kg}_{\mathrm{f}}$ for 30 seconds. Each of specimen was tested for 5 times indentation. The hardness tester was a CONTROLAB Universal Hardness Tester, Model D.0047, French.

c. Tensile Test

The tensile test was carried out by using a Tensilon RTF 2430 with a capacity of $30 \mathrm{kN}$ and crosshead speed of $0.0005-500 \mathrm{~mm} / \mathrm{min}$. The entirety of the tests were recorded by MSAT (Multi Signal Analysis Testing) data processing software and also included with PC data analysis, calculation and data storage for each testing mode. The speed for all configurations in the tensile test was 10 $\mathrm{mm} / \mathrm{min}$ 


\subsection{RESULT}

\subsection{Macroscopic Analysis}

Several macro and micro-scale features that were appeared on the fractography investigation of failure bolt can be seen in Figure 2.

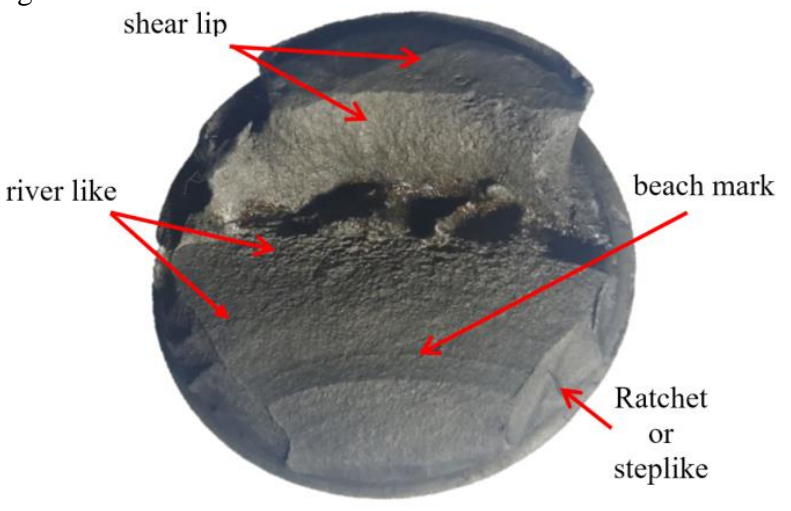

Figure 2: Macro and micro-scale features of failure bolt

In Figure 2 can be seen the failure was initiated by microcrack in a surface discontinuity region or the bolt thread. The single micro-crack turned into several micro-cracks to form a step like or ratchet. The ratchet was propagated in a flat progressive zone, which contained beach mark. The beach mark proved that the fracture was initiated and propagated by fatigue mechanism. The beach mark was also a sign that the service condition of the bolt had been stopped due to the operation shutdown or changes of the fluctuating load level [9]. Both of ratchet and beach mark were signs of cyclic load.

The river like feature was a sign of brittle fracture [10] which is analogous to as a 'river flow'. A number of small branches in the interior united to form an upstream, then propagated and triggered macro-crack on the exterior. The combination of upstream and micro-cracks at the initiation site caused the crack growth rate increased progressively and overload was occurred continuously. The remaining crosssectional area was not able to hold this mechanism, so the final fracture was occurred at the shear lip with high nominal stress characteristics.

\subsection{Microstructural Analysis}

The result of metallography examination is shown in Figure 3.

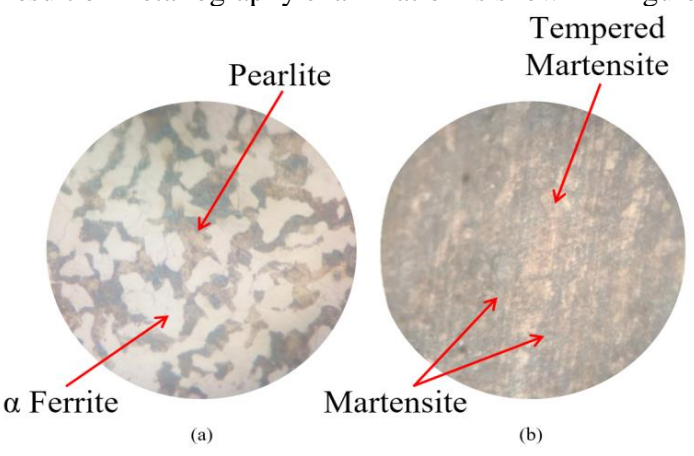

Figure 3: Microstructures of failure bolt (a) transversal and (b) longitudinal tangential section. 100x

From Figure 3a, it was recognized that the formation both of $\alpha$-ferrite and pearlite in the interior were resulted by slow cooling rate.
According to Callister [1], this due to during the cooling process, specimen was not possible to be cooled in the uniform rate, so that the specimen temperature on the exterior decreased faster than the interior. The martensitic structure of quenching and the tempered martensite structure of tempering as shown in Figure $3 \mathrm{~b}$ increased endurance limit of the failure bolt exterior because a tempered martensite structure provided the highest fatigue limit. The failure is estimated due to pearlite formation in the interior because the pearlitic structure, particularly those with coarse pearlite, has a poor fatigue resistance [11].

An endurance limit influenced the other fatigue parameters, i.e. fatigue strength and fatigue cycle. Decrease of the endurance limit after pearlite formation due to fatigue strength decreased. The lower of fatigue strength, so the application of load that can be accepted by hydraulic cylinder bolt also be lower. The application of load exceeded the endurance limit, where the fatigue cycle requirement was not reached.

\subsection{Hardness Test}

According to Vickers Hardness Number (HV) data, the specimens were classified into several conditions, showed in Table 1.

Table 1: Classification of specimen conditions according to HV

\begin{tabular}{ccc}
\hline Specimen & HV 62.5 & Condition \\
\hline New 1 & $300.57 \pm 4.06$ & Heat Treatment (HT) \\
New 2 & $303.50 \pm 4.36$ & \\
\hline New 3 & $165.44 \pm 1.08$ & Non-Heat Treatment \\
New 4 & $163.89 \pm 2.53$ & (NHT) \\
\hline New 5 & $297.71 \pm 5.28$ & Heat Treatment (HT) \\
New 6 & $298.67 \pm 5.49$ & Failure \\
\hline Failure & $232.06 \pm 8.55$ &
\end{tabular}

From Table 1, it was known the differences of treatment between specimen 3 and 4 to specimen 1, 2, 5 and 6 , which are processed from the new samples. The specimen 1, 2, 5 and 6 that be included in HT condition are estimated to be quenched and tempered.

Several factors may influence the hardness, i.e. temperature of heating, quenching media, holding time and tempering temperature [12]. The selection of heating temperature and quenching media were considered appropriate. From the holding time side, quenching is estimated to cause high material hardness. This caused the material brittleness and cannot be applied, so it had to be tempered [13].

In contrast to quenching, the hardness decreased by increasing of tempering holding time [14]. An increase of tempering temperature also needs to be considered because this factor increased ductility, but reduced the hardness and the ultimate tensile strength $\left(\sigma_{\mathrm{u}}\right)$ [15]. In addition, the failure bolt hardness of $232.06 \mathrm{HV}$ did not meet the requirement that was set by company, i.e. 45-50 HS or 326.1-368.7 HV [16].

\subsection{Tensile Test}

The engineering stress-strain curve of the new specimens are shown in figure 4 , with specimens are classified into 3 groups, that is group A consists of specimen 1, group B consists of specimen 2, 3 and 4 and group $C$ consists of specimen 5 and 6 . The group A is estimated as non-heat treated, while the group $\mathrm{B}$ is estimated as quenched and tempered. The group $\mathrm{C}$ are the specimens that being quenched during the study. Although the specimens of the group $\mathrm{C}$ got the same treatment, there is a quite different $\sigma_{\mathrm{u}}$ between both of specimens, so that specimen 
6 is estimated as the quenching result of group A, while specimen 5 is estimated as quenching result of group B.

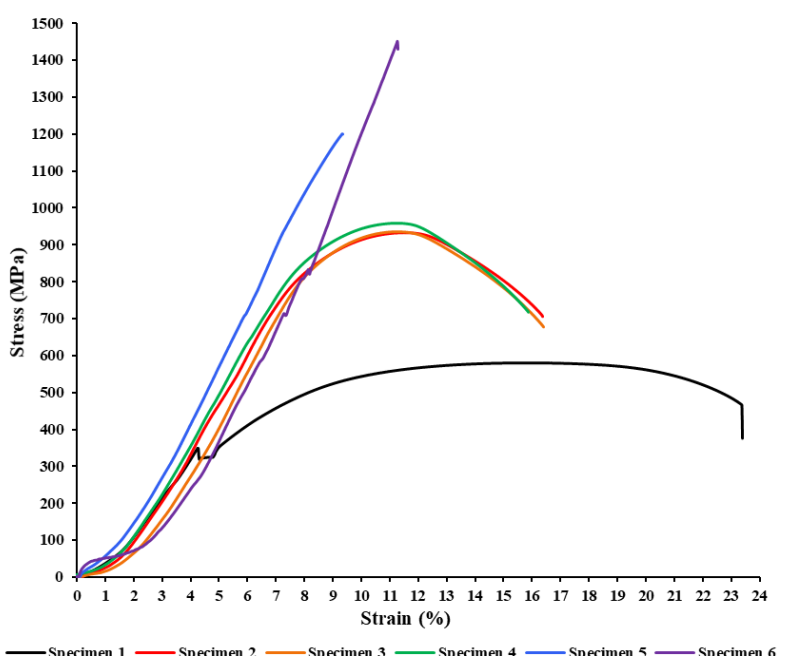

Figure 4: Engineering stress-strain curve of new specimens

The higher heating temperature and the longer holding time of tempering caused the decreasing of the hardness and the ultimate tensile strength, which is the goal of Q + T treatment could not be reached. This caused the decreasing of endurance limit, so the application of load that just a little above the endurance limit will reduce the life cycle of the hydraulic cylinder bolt.

\subsection{DISCUSSION}

Simulation test with service condition constraints was conducted according to the finite element method by using Autodesk Inventor Professional 2018 student version software. Several conditions that being constrained when data completion, that is:

- $\quad$ Steel alloy was chosen as override material.

- $\sigma_{\mathrm{y}}$ was chosen as safety factor.

- The $125.66 \mathrm{kN}$ axial load was used along the axis line.

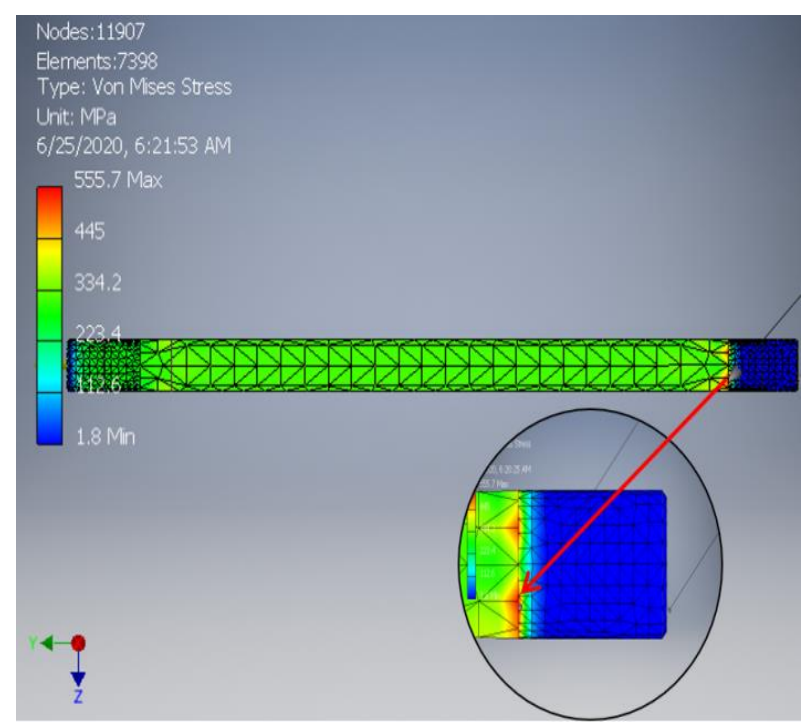

Figure 5: Result of simulation test with service condition
Based on the provisions above, the test result can be seen in Figure 5. From Figure 5, the simulation revealed the maximum stress of 555.7 MPa that was located at the boundary of undiscontinuity surface and the fixed constraint bolt thread. This information indicates an operating stress above 555.7 MPa has tendency of failure initiation at that location. This was confirmed by the failure bolt where the final fracture was occurred at the location as the indicated simulation.
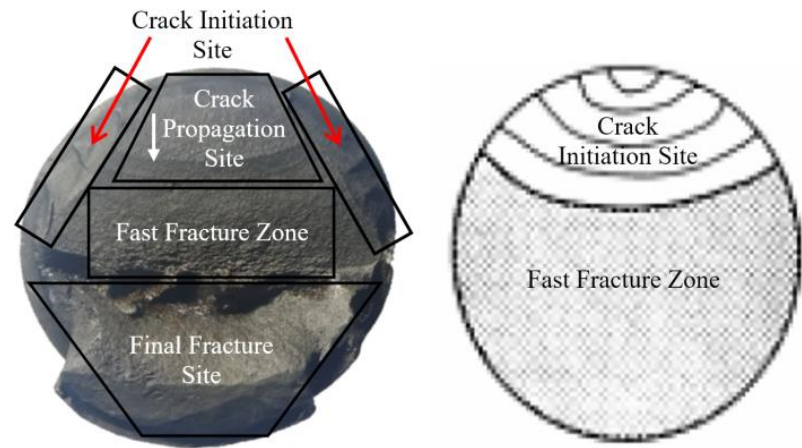

Figure 6: Comparison of failure bolt fracture to schematic of fatigue fracture according to ASM Handbook Volume 12

According to several tests that have been conducted, failure of hydraulic cylinder bolt is estimated as a low cycle fatigue failure. In order to confirm this estimation, the comparison in Figure 6 can be used.

According to Figure 6, the crack initiation sites show the failure of the hydraulic cylinder bolt was occurred with no stress concentration. The fast fracture zone about $2 / 3$ of the total failed cross-sectional area shows the fatigue zone, which contains macro- and microscale features is small. Both of those indications confirm the hypothesis of the hydraulic cylinder bolt failure mode due to the Low Cycle Fatigue (LCF) failure after high nominal stress application.

\subsection{CONCLUSION}

The low cycle fatigue is known as a failure mode of the hydraulic cylinder bolt. This is indicated by the presence of ratchet, beach mark, river mark and shear lip. The quite large size of shear lip indicates the application of high nominal stress.

The LCF failure mode is affected by low endurance limit. This is due to improper quenching and tempering treatment, so the martensite and tempered martensite are not formed in the whole part of the bolt. The highest endurance limit of tempered martensite was only formed for small amounts on the exterior with hardness of $232.06 \mathrm{HV}$ that did not meet the hardness requirement of the company. The lowest endurance limit of pearlitic structure was appeared for large amounts in the interior and caused a decrease of hardness from exterior to interior. The lower hardness would influence the lower tensile strength of bolt. The low hardness and tensile strength caused decreasing in fatigue cycle, so the final failure was occurred after a short period of fatigue cycle in the bolt thread.

In order to obtain the minimum hardness requirement, the AISI 4140 steel should be heat-treated by using suitable heat treatment, i.e. $850-860^{\circ} \mathrm{C}$ for 30 minutes and then oil quenched. For tempering process should be $540^{\circ} \mathrm{C}$ for $2.5-3$ hours. As the alternative material for hydraulic cylinder bolt, the AISI 4140 steel can be replaced with AISI 4063 steel because its higher endurance limit, about 600 to $800 \mathrm{MPa}$. 


\section{ACKNOWLEDGEMENTS}

Praised be to Allah because of His Mercy, this paper can be finished. Author great appreciation to the whole family, International Society of Ocean, Mechanical and Aerospace Scientists and Engineers as well as Material Testing Laboratory of Universitas Riau for supporting this research.

\section{REFERENCE}

[1] Callister, W.D.Jr. (2007). Material science and engineering an introduction ( $7^{\text {th }}$ ed). New York: John Wiley \& Sons, Inc.

[2] Molaei, S., Alizadeh, R., Attarian, M., \& Jaferian, Y. (2015). A failure analysis study on the fractured connecting bolts of a filter press, Case Studies in Engineering Failure Analysis 4, 26-38.

[3] Ibad, I.K. \& Rochiem, R. (2014). Analisa kegagalan baut piston VVCP gas kompresor gemini DS-504 EMP Malacca Strait SA, Jurnal Teknik Pomits 3(2), 180-184.

[4] Solomon, N., Solomon, I., Severin, T.L., Dulucheanu, C. \& Sanduleac, E. (2015). Compression press bolts failure analysis, TEHNOMUS-New Technologies and Products in Machine Manufacturing Technologies, 242-247.

[5] Bornmyr, A. \& Holmberg, B. (1995). Handbook for the pickling and cleaning of stainless steel. Avesta: Avesta Polarit Welding AB.

[6] ASTM E3 Standard practice for preparation of metallographic specimens. (1995). Pennsylvania: American Standard for Testing and Materials International.

[7] ASTM E8/E8M-16a Standard test methods for tension testing of metallic materials. (2016). Pennsylvania: American Standard for Testing and Materials International.

[8] ASTM E92 Standard test methods for vickers hardness and knoop hardness of metallic material. (2017). Pennsylvania: American Standard for Testing and Materials International.

[9] ASM Handbook Committee. (2002). ASM handbook volume 11 failure analysis and prevention. Materials Park, OH: American Society for Metals International.

[10] ASM Handbook Committee. (1987). ASM handbook volume 12 fractography. Ohio: American Society for Metals International.

[11] ASM Handbook Committee. (1990). ASM handbook volume 1: Properties and selection: Irons, steels, and high-performance alloys. In Bruce Boardman (Editor) Fatigue resistance of steels (p. 673-688). Ohio: American Society for Metals International.

[12] Suryo, S.H., Bayuseno, A.P., Paryanto, \& Pangeran, A.R (2018). Parameter optimization of heat treatment on AISI 4140 material hardness value for bucket teeth application using Taguchi method, Journal of Engineering and Applied Science, 13 (14), 5873-5880.

[13] Fendri, R., Darmawi, Syahrul \& Jasman (2018). Analisis sifat mekanik dan struktur mikro baja AISI 4140 akibat perbedaan temperatur pada perlakuan panas, Tempering, 37-47.

[14] Singh, G., Singh, R., \& Singh, R. (2015). To study the effect of holding time and holding temperature on hardness and microstructure of alloy steel AISI 4340, International Journal of Technology and Computing (IJTC), 1(1), 10-21.
[15] ASM Handbook Committee. (2004). ASM handbook volume 9 metallography and microstructures. Materials Park, OH: American Society for Metals International.

[16] ASTM E140 Standard hardness conversion tables for metals relationship among brinell hardness, vickers hardness, rockwell hardness, superficial hardness, knoop hardness and scleroscope hardness. (2007). Pennsylvania: American Standard for Testing and Materials International. 